\title{
Analisa Awal Kekasaran Permukaan Hasil Produksi Mesin Cetak Tiga Dimensi Terhadap Pengaruh Variasi Grit Size Sand Paper
}

\author{
Rahman Hakim ${ }^{a *}$, Nanang Ali Sutisna ${ }^{\mathrm{b} \#}$ \\ a Jurusan Teknik Mesin, Politeknik Negeri Batam \\ Jalan A. Yani, Batam Center, Kota Batam, Provinsi Kepulauan Riau, Indonesia. \\ "E-mail: hakim@ polibatam.ac.id \\ brogram Studi Teknik Mesin, Universitas Presiden \\ J1 Ki Hajar Dewantara, Jababeka Education Park, Cikarang, West Java, 17550, Indonesia \\ \#E-mail: nanang.ali@president.ac.id
}

\begin{abstract}
The three-dimensional printing one of FDM (Fused Deposition Modeling) type by using PLA material (Polylactid Acid) which is classified as polymer material generally has a rough surface. It requires final work to make the surface smoother. The purpose of this experiment is to find out which size of Grit Size can produce the lowest surface roughness value or in other words has the highest surface smoothness value. One way is to use paper sand with variations in the Grit Size level that is usually displayed in the numeric code on the scrub paper label. In this experiment, we used Grit Size with a size of 1000CW, $1200 \mathrm{CW}$ and $1500 \mathrm{CW}$. The test parameters on the three-dimensional printing machine with the Leapfrog Creatr HS brand use PLA with a diameter of $1.75 \mathrm{~mm}$, with a Nozzle and Base Plate temperature of $230^{\circ} \mathrm{C}$ and $30^{\circ} \mathrm{C}$, and have a feedrate and infill density of $70 \%$. After three attempts to retrieve the data, we got the results which by using sand paper with grit size $1500 \mathrm{CW}$ had the lowest surface roughness (Ra) value, which was $4.392 \mu \mathrm{m}(\mathrm{N} 8)$.
\end{abstract}

Keywords: Leapfrog creatr HS; polylactid acid (PLA); sand paper; surface roughness (Ra)

\section{Abstrak}

Hasil produksi cetak tiga dimensi tipe FDM (Fused Deposition Modeling) dengan menggunakan material PLA (Polylactid Acid) yang tergolong material polymer pada umumnya mempunyai permukaan yang kasar sehingga memerlukan pekerjaan akhir untuk membuat permukaanya lebih halus lagi. Tujuan percobaan ini ialah untuk mengetahui ukuran Grit Size mana saja yang bisa menghasilkan nilai kekasaran permukaan yang paling rendah atau dengan kata lain mempunyai nilai kehalusan permukaan yang paling tinggi. Salah satu caranya ialah dengan menggunakan kertas gosok dengan variasi tingkat Grit Size yang biasa ditampilkan pada kode angka pada label kertas gosok. Pada percobaan kali ini, kami menggunakan Grit Size dengan ukuran 1000CW, 1200CW dan 1500CW. Parameter uji pada mesin cetak tiga dimensi dengan merek Leapfrog Creatr HS ini menggunakan PLA berdiameter $1.75 \mathrm{~mm}$, dengan temperatur Nozzle dan Base Plate sebesar $230^{\circ} \mathrm{C}$ dan $30^{\circ} \mathrm{C}$, serta mempunyai feedrate dan infill density masingmasing sebesar $70 \%$. Setelah dilakukan percobaan sebanyak tiga kali pengambilan data, kami dapatkan hasil yang dimana dengan menggunakan sand paper dengan grit size $1500 \mathrm{CW}$ mempunyai nilai kekasaran permukaan (Ra) yang paling rendah, yaitu sebesar 4,392 $\mu \mathrm{m}(\mathrm{N} 8)$.

Kata kunci: Leapfrog creatr HS; polylactid acid (PLA); kertas gosok; nilai kekasaran permukaan (Ra)

\section{Pendahuluan}

Penggunaan teknologi Fused Deposition Modeling (FDM) mengalami perkembangan yang signifikan, tidak hanya sebatas pada pengujian di laboratorium [1], [2], namun sudah kearah yang lebih praktis digunakan oleh masyarakat, baik untuk pemodelan tiga dimensi dibidang action figure, medical needs [3] bahkan sampai ke bidang property [4], khususnya teknologi Additive Manufacturing (AM) atau lebih dikenal sebagai teknologi printer tiga dimensi yang menggunakan bahan baku polymer [5]. Penerapan teknologi pemodelan tiga dimensi dengan menggunakan material polymer ini sering digunakan oleh klub aeromodelling untuk pembuatan spare parts mesin yang sudah discontinue maupun import, pembuat maket perumahan didalam showcase kaca, maupun pembuatan pengganti gypsum untuk penyangga tulang yang retak [3], [5], [6].

Polylactid Acid (PLA) merupakan salah satu jenis thermoplastic polymer yang paling banyak digunakan untuk pembuatan model tiga dimensi. Selain mempunyai titik leleh yang rendah yaitu pada temperature 190 ${ }^{\circ} \mathrm{C}$ [7], juga mempunyai sedikit bau yang dihasilkan jika dibandingkan dengan jenis Acrylonitrile Butadiene Styrene (ABS) [1], [8] sebesar $240^{\circ}$ C. Penelitian sebelumnya yang dilakukan oleh Benny ditahun 2019, material ABS mempunyai nilai 
kekasaran permukaan yang paling rendah yaitu $6,15 \mu \mathrm{m}$ pada temperatur nozzle dan base plate sebesar $260^{\circ} \mathrm{C}$ dan $100^{\circ}$ $\mathrm{C}$ yang disertai dengan penggunaan lem pada base plate-nya [9]. Berbeda dengan material PLA mempunyai nilai kekasaran permukaan yang paling rendah yaitu $5.709 \mu \mathrm{m}$ pada temperature nozzle dan base plate sebesar $190^{\circ} \mathrm{C}$ dan $30^{\circ} \mathrm{C}$ yang disertai dengan penggunaan lem pada base plate-nya [7].

Kekasaran permukaan hasil cetak tiga dimensi dengan nilai $5.709 \mu \mathrm{m}$ secara visual masih kasar dan kurang memiliki nilai jual [10]. Salah satu cara yang akan dilakukan oleh penulis kali ini adalah dengan melakukan post processing dengan cara melakukan proses penghalusan permukaan produk cetak tiga dimensi dengan menggunakan sand paper dengan tingkatan Grit Size yang berbeda. Adapun tujuan penelitian perdana ini adalah untuk analisa awal nilai kekasaran permukaan pada produk mesin cetak tiga dimensi jika dilakukan proses polishing dengan menggunakan sand paper berbeda grit size. Penggunaan specimen uji pada percobaan kali ini ditujukan untuk membuat produk akhir yang mempunyai surface finish yang layak jual dan permukaan permukaannya bisa glossy [11]. Sebanyak tiga buah specimen uji, dilakukan dan digunakan perumusan nilai rata-rata untuk mendapatkan kesimpulan data yang akan dibandingkan.

\section{Material dan Metode Penelitian}

\subsection{Pembuatan Spesimen Uji}

Proses pembuatan specimen dilakukan dengan proses layer by layer. Seperti dijelaskan pada Gambar 1, prinsip kerja dari printer tiga dimensi dimulai dari gulungan material PLA di dalam spool yang diteruskan di nozzle sampai pada build plat form, atau biasa dikenal sebagai base plate. Dimensi dari specimen yang akan digunakan pada percobaan ini adalah dengan ukuran $100 \mathrm{~mm}$ x $20 \mathrm{~mm}$, berbentuk jajaran genjang.

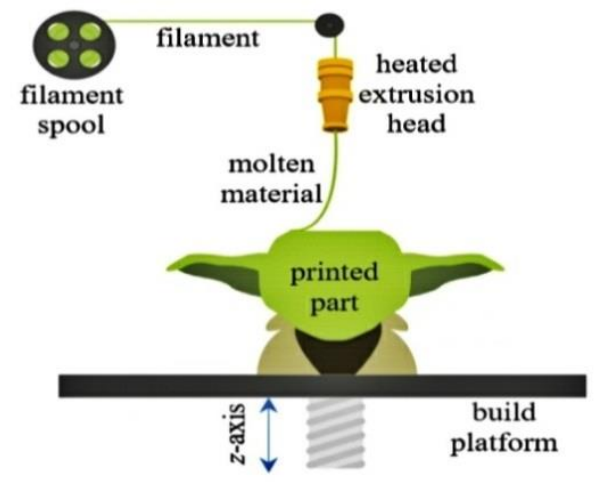

Gambar 1. Prinsip kerja 3D printing Fused deposition modeling (FDM) [11].

\subsection{Penentuan Parameter Experimental Study}

Parameter pengujian yang akan dilaksanakan adalah sebagai berikut (a) mesin cetak tiga dimensi, merk: Leapfrog Creatr HS tipe dual-nozzle, (b) material filament jenis PLA dengan diameter $1,75 \mathrm{~mm}$, (c) temperatur nozzle $220^{\circ} \mathrm{C}$, temperature base plate $30^{\circ} \mathrm{C}$ [7] dan menggunakan sand paper dengan grit size yang berbeda mulai dari 1.000; 1.200 ; dan 1.500. Sebagai data pembanding, nilai kekasaran permukaan secara umum untuk proses extrusion mempunyai nilai kekasaran permukaan sebesar 0,16 $\mu \mathrm{m}$ sampai dengan 5,0 $\mu \mathrm{m}$ [12]. Oleh karena itu, melalui experiment ini diharapkan mempunyai nilai kekasaran permukaan sama atau bahkan lebih rendah dari $0,16 \mu \mathrm{m}$

Tabel 1. Tabel Standar Kekasaran Permukaan Multi Proses [12]

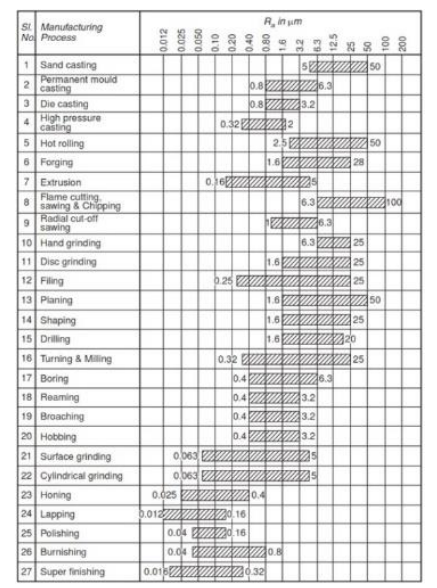




\subsection{Proses Pengambilan Data}

Data kekasaran permukaan diambil sebanyak tiga kali, dan dirata-rata dengan menggunakan persamaan (1). Pada Gambar 2, menjelaskan tentang alat uji kekasaran permukaan, dan arah pergerakan probe yang tegak lurus dengan arah serat. Gambar 3 menjelaskan tentang cara pengambilan data specimen uji sebanyak tiga kali pengambilan data yang selanjutnya akan dirata-rata.

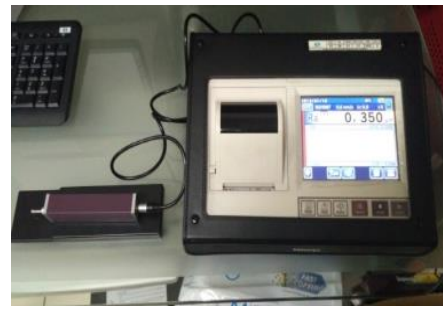

(a)

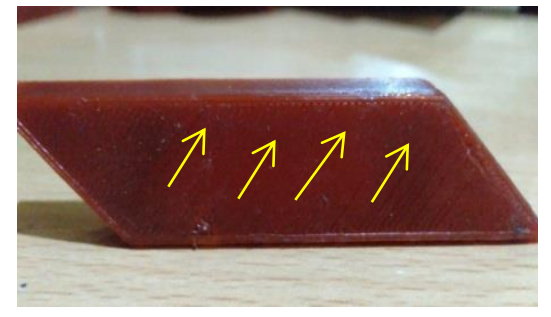

(b)

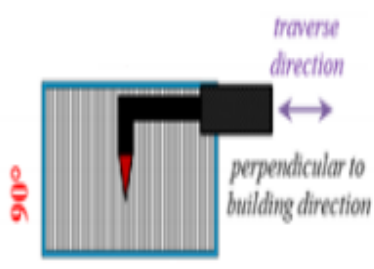

(c)

Gambar 2. (a) Surface Roughness Tester, Mitoyo SJ-310 (b) Spesimen uji dan arah penarikan probe kekasaran permukaan, (c) Arah pergerakan probe tegak lurus dari arah serat specimen uji. [11]
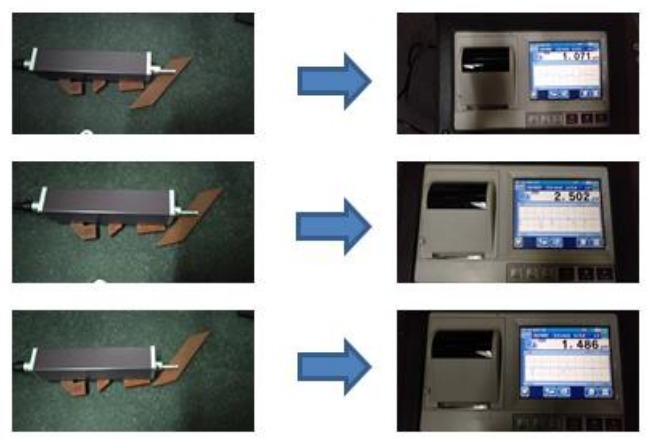

Gambar 3. Dokumentasi pengambilan data kekasaran permukaan pada specimen uji

\subsection{Pengolahan Data}

Sebanyak tiga kali pengambilan data kekasaran permukaan, diolah dengan ilmu statistic, rata-rata sederhana. Setelah itu akan dibandingkan hasil rata-ratanya dengan nilai rata-rata dari Grit Size yang lainnya. Sedangkan untuk membandingkan hasil rata-rata dari multi-variable dirumuskan dengan menggunakan Standar Deviasi.

$$
\begin{aligned}
& \bar{X}=\frac{X_{1}+X_{2}+X_{3}}{n} \\
& s=\sqrt{\frac{\sum(X-\bar{X})^{2}}{n-1}}
\end{aligned}
$$

\subsection{Pembuatan Produk Akhir}

Setelah didapatkan hasil kekasaran permukaan yang terendah setelah dilakukan post processing dengan sand paper, maka akan dilanjutkan ke rencana awal yaitu membuat produk jadi yang siap jual di masyarakat. Gambar 4 menjelaskan tentang produk akhir berbentuk jam dinding raksasa yang berfungsi sebagai art of de wall di rumah tangga.

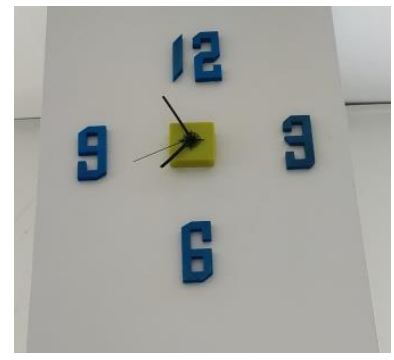

Gambar 4. Produk akhir aksesoris rumah tangga - jam dinding raksasa 


\section{Hasil dan Pembahasan}

Setelah melakukan proses pengambilan data sebanyak tiga kali replikasi, didapatkan hasil sebagai berikut. Pada Gambar 5 dapat disimpulkan bahwa produk original yang telah di amplas menggunakan sand paper dengan Grit Size 1.000 yang diukur berdasarkan tiga titik pengukuran, dan didapatkan rata-rata Ra sebesar $12.120 \mu \mathrm{m}$. Hal ini memang terdapat perbedaan secara signifikan jika dibandingkan dengan nilai rata-rata Ra produk Original hasil cetak tiga dimensi sebesar $30.045 \mu \mathrm{m}$.

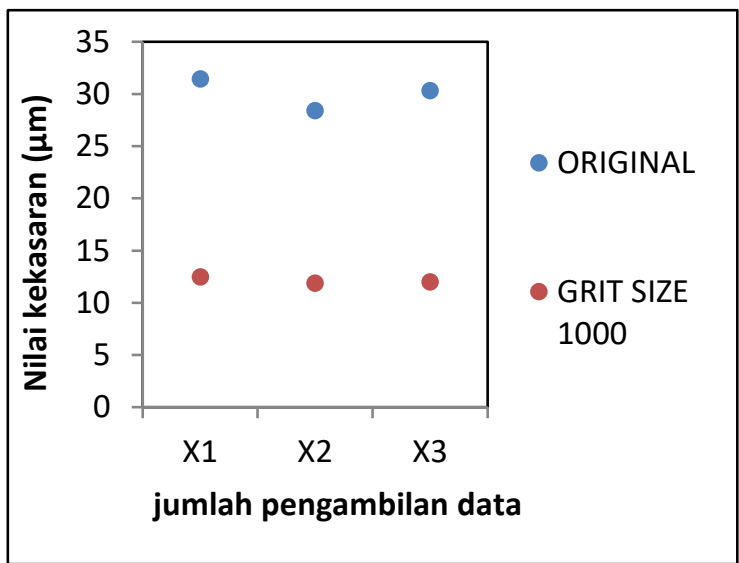

Gambar 5. Nilai surface roughness ( $\mathrm{Ra}$ ) produk original yang telah diamplas menggunakan sand paper dg grit size

$$
1.000 \mathrm{CW}
$$

Sedangkan pada Gambar 6 didapatkan hasil bahwa produk original yang telah di amplas menggunakan sand paper dengan Grit Size 1.200 yang diukur berdasarkan tiga titik pengukuran, dan didapatkan rata-rata Ra sebesar $6.665 \mu \mathrm{m}$. Hal ini memang terdapat perbedaan secara signifikan jika dibandingkan dengan nilai rata-rata Ra produk Original hasil cetak tiga dimensi sebesar $30.045 \mu \mathrm{m}$.

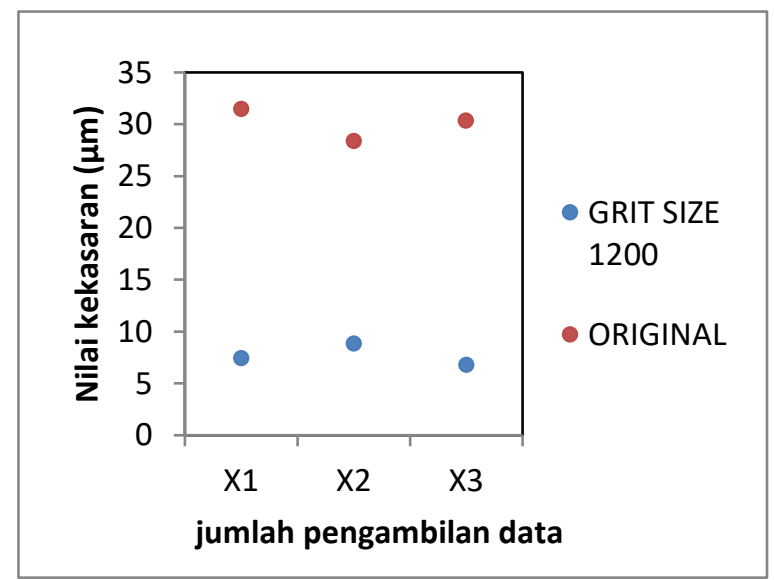

Gambar 6. Nilai surface roughness ( $\mathrm{Ra}$ ) produk original yang telah diamplas menggunakan sand paper dg grit size $1.200 \mathrm{CW}$

Gambar 7 di dapatkan hasil bahwa produk original yang telah di amplas menggunakan sand paper dengan Grit Size 1.500 yang diukur berdasarkan tiga titik pengukuran, dan didapatkan rata-rata Ra sebesar $4.392 \mu$ m. Hal ini memang terdapat perbedaan secara signifikan jika dibandingkan dengan nilai rata-rata Ra produk Original hasil cetak tiga dimensi sebesar $30.045 \mu \mathrm{m}$. 


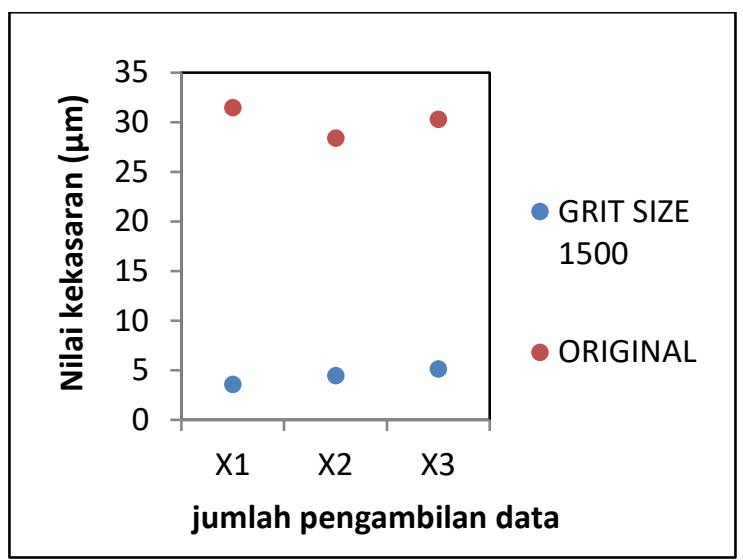

Gambar 7. Nilai surface roughness $(\mathrm{Ra})$ produk original yang telah diamplas menggunakan sand paper dg grit size $1500 \mathrm{CW}$

Tabel 2 merupakan perbandingan nilai rata-rata surface roughness Ra, baik dalam kondisi original, maupun sudah dilakukan proses penghalusan permukaan dengan menggunakan sand paper dg grit size 1000CW, 1200CW dan $1500 \mathrm{CW}$. Dari tabel tersebut didapatkan hasil nilai kekasaran permukaan yang paling rendah adalah ada pada Grit Size 1500CW sebesar $4.392 \mu \mathrm{m}$ dengan standar deviasi (s) sebesar 11.440 .

Tabel 2. Tabel perbandingan nilai kekasaran permukaan produk cetak tiga dimensi dengan grit size $1000 \mathrm{CW}, 1200 \mathrm{CW}$ dan $1.500 \mathrm{CW}$.

\begin{tabular}{lllll}
\hline $\begin{array}{l}\text { Nilai Kekasaran } \\
\text { Permukaan }(\text { Ra) }\end{array}$ & $\begin{array}{l}\text { X1 } \\
(\mu \mathrm{m})\end{array}$ & $\begin{array}{l}\mathbf{X 2} \\
(\mu \mathrm{m})\end{array}$ & $\begin{array}{l}\mathbf{X 3} \\
(\mu \mathrm{m})\end{array}$ & $\begin{array}{l}\text { X_bar } \\
(\mu \mathrm{m})\end{array}$ \\
\hline Original & 31.445 & 28.384 & 30.306 & 30.045 \\
Grit Size 1000CW & 12.487 & 11.867 & 12.008 & 12.120 \\
Grit Size 1200CW & 7.409 & 8.817 & 6.770 & 7.665 \\
Grit Size 1500CW & 3.581 & 4.452 & 5.142 & 4.392 \\
\hline
\end{tabular}

\section{Kesimpulan}

Setelah didapat hasil dari setiap metode pengujian yang berbeda dengan referensi nilai kekasaran standard proses extrusin 0,16 sampai dengan $5 \mu \mathrm{m}$ dengan menggunakan parameter setting temperatur nozzle $220^{\circ} \mathrm{C}$, dan base plate $30^{\circ}$ $\mathrm{C}$ dengan menggunakan sand paper dengan tingkatan kekasaran (Grit Size) yang berbeda mulai dari $800 \mathrm{CW} ; 1.000 \mathrm{CW}$ dan 1.200 CW. Didapatkan kesimpulan bahwa sand paper dengan grit size $1.000 \mathrm{CW}$ memiliki nilai kekasaran permukaan (Ra) sebesar 12,120 $\mu \mathrm{m}$, dengan standar deviasi sebesar 12.675; sand paper dengan grit size $1.200 \mathrm{CW}$ memiliki nilai kekasaran permukaan (Ra) sebesar $7.665 \mu \mathrm{m}$, dengan standar deviasi sebesar 11.846; dan sand paper dengan grit size $1.500 \mathrm{CW}$ memiliki nilai kekasaran permukaan (Ra) sebesar $4.392 \mu \mathrm{m}$, dengan standar deviasi sebesar 11.440. Untuk mendapatkan hasil kekasaran permukaan dibawah nilai $4.00 \mu \mathrm{m}$, bisa dipastikan terlebih dahulu, proses produksinya apakah menggunakan jenis dan ukuran nozzle yang atau berbeda. Karena Diameter nozzle merupakan salah satu parameter terpenting yang bisa mempengaruhi nilai kekasaran permukaan produk hasil cetak tiga dimensi.

\section{Ucapan Terima Kasih}

Terima kasih kami ucapkan kepada Universitas Presiden melalui penulis kedua yang telah membantu dana maupun penyempurnaan tulisan pada experiment pertama ini. Serta kepada Politeknik Negeri Batam yang telah memfasilitasi dan mendukung secara penuh baik sarana maupun prasarana pendukung terselesainya experiment ini.

\section{Daftar Pustaka}

[1] D. Sulayman, "Pengaruh Suhu dari Heater Nozzle Terhadap Produk Printer 3D," Universitas Muhammadiyah Surakarta, 2015.

[2] Babagowda, R. S. Kadadevara Math, R. Goutham, and K. R. Srinivas Prasad, "Study of Effects on Mechanical Properties of PLA Filament which is blended with Recycled PLA Materials," IOP Conf. Ser. Mater. Sci. Eng., vol. 310, no. 1, 2018.

[3] M. L. Smith and J. F. X. Jones, "Dual-extrusion 3D Printing of Anatomical Models for Education," Anat. Sci. Educ., Vol. 11, No. 1, pp. 65-72, 2018.

[4] D. R. Howeidy and Z. Arafat, "The Impact of Using 3D Printing on Model Making Quality and Cost in the Architectural Design Projects,” Int. J. Appl. Eng. Res., Vol. 12, No. 6, pp. 987-994, 2017.

[5] K. Tappa and U. Jammalamadaka, "Novel Biomaterials Used in Medical 3D Printing Techniques," J. Funct. Biomater., Vol. 9, No. 1, 2018. 
[6] D. Mitsouras et al., "Medical 3D Printing for the Radiologist," RadioGraphics, Vol. 35, No. 7, pp. 1965-1988, 2015.

[7] R. Hakim, I. Saputra, G. P. Utama, and Y. Setyoadi, "Pengaruh Temperatur Nozzle dan Base Plate pada Material PLA terhadap Nilai Masa Jenis dan Kekasaran Permukaan Produk pada Mesin Leapfrog Creatr 3D Printer," J. Teknol. dan Ris. Terap., Vol. 1, No. 1, 2019.

[8] Z. Quan et al., "Printing Direction Dependence of Mechanical Behavior of Additively Manufactured 3D Preforms and Composites," Compos. Struct., Vol. 184, pp. 917-923, 2018.

[9] B. H. Irawan, R. Hakim, H. Widiastuti, D. Kamsyah, and B. Sahputra, "Pengaruh Temperatur Nozzle dan Base Plate pada Mesin Leapfrog Creatr 3d Printer terhadap Density dan Surface Roughness Material ABS," J. Teknol. dan Ris. Terap., Vol. 1, No. 1, 2019.

[10] A. Farzadi et al., "3D Printed PLA Scaffolds to Promote Healing of Large Bone Defects,” Sci. Rep., Vol. 06, No. 01, pp. 139-148, 2017.

[11] M. S. Alsoufi and A. E. Elsayed, "How Surface Roughness Performance of Printed Parts Manufactured by Desktop FDM 3D Printer with PLA+ is Influenced by Measuring Direction,” Am. J. Mech. Eng., Vol. 5, No. 5, pp. 211-222, 2017.

[12] Z. Uddin, "Kekasaran Permukaan atau Tanda Pengerjaan pada Gambar Teknik,” www.omesin.com, 2018. [Online]. Available: http://www.omesin.com/2018/08/kekasaran-permukaan-atau-tanda.html. 